\title{
What do the White Spots in the Second Part of Duodenum Tell Us?
}

\author{
Ozge Kurtkulagi ${ }^{1,}$, Ozlem Yonem ${ }^{2}$, Hatice Terzi ${ }^{3}$, Engin Altinkaya², Ozgur Kurtkulagi ${ }^{4}$ \\ ${ }^{1}$ Department of Internal Medicine, Bolu Abant Izzet Baysal University, Faculty of Medicine, Bolu, Turkey. \\ ${ }^{2}$ Department of Gastroenterology, Faculty of Medicine, Cumhuriyet University, Sivas, Turkey. \\ ${ }^{3}$ Department of Hematology, Faculty of Medicine, Cumhuriyet University, Sivas, Turkey. \\ ${ }^{4}$ Department of General Surgery, Bolu Abant Izzet Baysal University, Faculty of Medicine, Bolu, Turkey.
}

\begin{abstract}
Objective: The underlying conditions/diseases of scattered white spots in the duodenum are rather not very clear in the literature. We aimed to find out whether Helicobacter pylori, diabetes mellitus or inflammation has an impact on the presence of duodenal white spots.
\end{abstract}

Materials \& Methods: We included all patients who underwent endoscopy between the time-period 2007-2017 in the Endoscopy Unit of Cumhuriyet University and had scattered white spots in the duodenum. Our control group was formed by randomly selected patients who underwent endoscopy at the same time period in whom duodenal biopsy was taken. The demographic data of both the patient and the control group, the presence of diabetes, endoscopic and histological diagnoses, neutrophil lymphocyte ratio, thrombocyte lymphocyte ratio, mean platelet volume and erythrocyte distribution width were obtained from the computer system of the hospital in detail.

Results: Peptic ulcer disease was found to be significantly more prevalent in patients with white spots than the control group. We could not find any difference between the patient and control groups by means of either neutrophil lymphocyte ratio, platelet lymphocyte ratio, mean platelet volume and erythrocyte distribution width, Helicobacter pylori, positivity or presence of diabetes.

Conclusion: Both diabetes mellitus and H. pylori are causes of systemic inflammation. In our study, we evaluated whether patients with white spots were associated with systemic inflammation by looking at popular inflammation markers. We could not find any difference between the two groups in terms of these markers.

Keywords: White spots, Duodenum, Diabetes mellitus, Systemic inflammation, Lymphangiectasia, Giardiasis, Chronic nonspecific duonetitis.

\section{INTRODUCTION}

The scattered white spots on the duodenum is a relatively rare endoscopic finding during upper gastrointestinal endoscopy [1]. There is no exact definition of white spots in the literature, it is a visual finding identified at the endoscopy procedure. Although its pathogenesis is not known, there are publications showing that these white spots have been seen in patients with giardia, lymphangiectasia and chronic nonspecific duonetitis [2-4]. There is a great variation among studies. The other unknown area about duodenal white spots is the issue of underlying conditions. Both Helicobacter pylori (H. pylori) and diabetes mellitus (DM) can induce chronic inflammation in the body and we don't whether chronic inflammation can be an underlying condition for duodenal white spots.

For this reason, we performed this study to delineate the most prevalent endoscopic and histopathological findings that have co-existence with duodenal white spots and also to determine whether the associated conditions such as H. pylori, diabetes mellitus and inflammation which we investigated by popular serum markers like neutrophil lymphocyte ratio (NLR), platelet lymphocyte ratio (PLR), mean platelet volume (MPV) and erythrocyte distribution width (RDW) have an impact on the

*Address correspondence to this author at the Department of Internal Medicine, Bolu Abant Izzet Baysal University, Faculty of Medicine, Bolu, Turkey. Email: ozgekurtkulagi@gmail.com presence of duodenal white spots. As far as we have searched this is the first study in the literature that investigates these correlations.

\section{MATERIALS AND METHODS}

In present retrospective study, we included all patients who underwent endoscopy between the time-period 2007-2017 in the Endoscopy Unit of Cumhuriyet University and had scattered white spots in the duodenum, by random sampling. Patients were determined retrospectively by examining them from hospital files. Our control group was formed by randomly selected patients who underwent endoscopy at the same time period. The number of subjects in the study and control group was 205 each respectively. Following an at least 8-hour fasting upper gastrointestinal endoscopy was performed on each patient. Written informed consent was obtained prior to each procedure from all patients. After premedication with topical anesthesia of the oropharynx, patients assumed the left lateral decubitus position. At least two duodenal biopsies were obtained from the second part of the duodenum for histological investigation. Gastric antrum biopsy specimens (at least two biopsies) were also obtained from all participants. Duodenal biopsy was taken from the control group due to indications other than white spots.

Demographic data, presence of chronic disease, endoscopic 
and histological diagnoses of both the patient and control groups were noted, and complete blood count results were obtained through the hospital computer recording system. Patients under 18 and over 80 years old and pregnant women were not included in the study, neither in study nor in control group.

\section{STATISTICAL ANALYSIS}

The statistical analyses were conducted with SPSS software (SPSS 22.0 for Widows, IBM, Chicago, IL, USA). Analyses of the variables whether they show normal distribution or not between study groups were done with Kolmogorov Smirnov test. Independent samples $t$ test was used in comparison of the variables with normal distribution and these variables were expressed as mean \pm standard deviation. Comparison of the categorical variables were done with chi-square test and expressed as $n$ (percentage). Statistical significance level was set on a p-value lower than 0.05 .

\section{RESULTS}

In this study, peptic ulcer were found in $21(10.2 \%)$ of the patients with white spots, and in 9 (4.4\%) of the control group patients respectively and this was significantly important $(\mathrm{p}=0.023)$. There was no difference by means of age, gender, $\mathrm{DM}$, and anemia between the two groups (Table 1). We also did not find any difference between the two groups by means of the chronic inflammation parameters derived from the complete blood count such as, neutrophil lymphocyte ratio (NLR), platelet lymphocyte ratio (PLR), mean platelet volume (MPV) and erythrocyte distribution width (RDW) (Table 2). There was no difference by means of the presence of gastritis, duodenitis, esophagitis, lower esophageal sphincter (LES) relaxation, hiatal hernia, or erosive gastritis between the two groups (Table 3 ). We also did not find any difference between the two groups by means of the gastric histological findings such as atrophy, intestinal metaplasia, chronic gastritis and H. Pylori presence (Table 3). Duodenal biopsy results such as, non-specific duodenitis, giardiasis and lymphangiectasia were also not significantly different between the two groups (Table $\mathbf{3}$ ).

Table 1. Demographic Data of Control and Study Groups.

\begin{tabular}{|l|c|c|c|}
\hline & $\begin{array}{c}\text { Study group } \\
(\mathbf{n = 2 0 5})\end{array}$ & $\begin{array}{c}\text { Control group } \\
(\mathbf{n}=\mathbf{2 0 5})\end{array}$ & p-value \\
\hline Age (years) & $53.36 \pm 16.37$ & $54.74 \pm 17.20$ & 0.404 \\
\hline Gender & & & \\
\hline Woman (n (\%)) & $115(\% 56.1)$ & $102(\% 49.3)$ & 0.166 \\
Man (n (\%)) & $90(\% 43.9)$ & $103(\% 50.7)$ & \\
\hline DM (n (\%)) & $23(\% 11.2)$ & $15(\% 7.3)$ & 0.173 \\
\hline Anemia (n (\%)) & $53(\% 25.9)$ & $67(\% 32.7)$ & 0.129 \\
\hline
\end{tabular}

Table 2. Chronic Inflammation Parameters in the Control and Study Groups.

\begin{tabular}{|l|c|c|c|}
\hline & $\begin{array}{c}\text { Study group } \\
(\mathbf{n = 2 0 5})\end{array}$ & $\begin{array}{c}\text { Control group } \\
(\mathbf{n = 2 0 5})\end{array}$ & p-value \\
\hline NLR (\%) & $3.07 \pm 4.50$ & $3.35 \pm 3.54$ & 0.263 \\
\hline PLR (\%) & $148.56 \pm 87.01$ & $152.12 \pm 76.58$ & 0.188 \\
\hline MPV (fL) & $9.40 \pm 1.30$ & $9.36 \pm 1.24$ & 0.408 \\
\hline RDW (\%) & $14.28 \pm 2.16$ & $14.47 \pm 2.69$ & 0.431 \\
\hline
\end{tabular}

(NLR: Neutrophil Lymphocyte Ratio, PLR: Platelet Lymphocyte Ratio, MPV: Mean Platelet Volume and RDW: Red Cell Distribution Width).

Table 3. Endoscopic and Histopathological Findings in Control and Study Groups.

\begin{tabular}{|l|c|c|c|}
\hline Endoscopic Findings & $\begin{array}{c}\text { Study group } \\
(\mathbf{n = 2 0 5})\end{array}$ & $\begin{array}{c}\text { Control group } \\
(\mathbf{n = 2 0 5})\end{array}$ & p-value \\
\hline Gastritis (n (\%)) & $165(\% 80.5)$ & $174(\% 84.9)$ & 0.240 \\
\hline Peptic ulcer (n (\%)) & $21(\% 10.2)$ & $9(\% 4.4)$ & $0.023 *$ \\
\hline Duodenit (n (\%)) & $9(\% 4.4)$ & $16(\% 7.8)$ & 0.149 \\
\hline Esophagitis (n (\%)) & $47(\% 22.9)$ & $61(\% 29.8)$ & 0.116 \\
\hline LES Relaxation (n (\%)) & $61(\% 29.8)$ & $59(\% 28.8)$ & 0.828 \\
\hline Hiatal hernia (n (\%)) & $19(\% 9.3)$ & $14(\% 6.8)$ & 0.364 \\
\hline Erosive gastritis (n (\%)) & $10(\% 4.9)$ & $7(\% 3.4)$ & 0.457 \\
\hline Gastric Histopathological Findings & $61(\% 29.8)$ & $64(\% 31.3)$ & 0.755 \\
\hline Atrophy (n (\%)) & $55(\% 27)$ & $40(\% 19.8)$ & 0.900 \\
\hline Intestinal metaplasia (n (\%)) & $199(\% 97.4)$ & $194(\% 94.9)$ & 0.191 \\
\hline Chronic gastritis (n (\%)) & $129(\% 63.3)$ & $127(\% 62.4)$ & 0.865 \\
\hline Helicobacter pylori (n (\%)) & $2(\% 1)$ & $0(\% 0)$ & 0.289 \\
\hline Duodenal Histopathological Findings & $0(\% 0)$ & 0.290 \\
\hline Duodenal mucosa (n (\%)) & $49(\% 25.3)$ & $7(\% 22.6)$ & 0.345 \\
\hline Non-specific duodenitis (n (\%)) & $138(\% 71.1)$ & $23(\% 74.2)$ & 0.468 \\
\hline Giardiasis (n (\%)) & $2(\% 1)$ & \\
\hline Lymphangiectasia (n (\%)) & $2 \%$ & \\
\hline
\end{tabular}

* Statistically significant.

\section{DISCUSSION}

White spots is a visual finding determined by the endoscopist. It is also defined by some gastroenterologists as a view of salt thrown in the duodenum. As the associated conditions accompanying this lesion is not clear in the literature; we conducted this study and found that peptic ulcer disease is significantly more common than the control group in these patients. We also investigated whether diabetes mellitus or chronic inflammation parameters derived from the complete blood count have any impact on the prevalence of white spots and could not find a significant difference between the study and control groups.

The demographic findings of our study group yielded a slight 
female predominant middle-aged profile of patients. We also used a control group in our study and found no difference by means of age and sex between the study and control groups. The number of subjects in each group was 205. In a similar study conducted by Biyikoglu et al. which aimed to show the spectrum of pathologies in patients with duodenal white spots; we can see that female predominance is overt in this study $(65.5 \%$ vs $34.5 \%)$ and the patients are mostly middle-aged. But this study included a lesser number of patients with no control group [2]. In our study, we compared the results of duodenum and gastric biopsy results of our patient and control groups. While the most common lesion was gastritis in both the study and control groups; peptic ulcer disease was significantly more common in the study group than the control group. Chronic gastritis and chronic non-specific duodenitis were the most common histopathological diagnoses of our study group. In the study of Tas et al. just as it was in our study the most common duodenal histopathology was chronic non-specific duodenitis while it was intestinal lymphangiectasia in the study of Biyikoglu et al. [2].

In our study, we compared the incidence of DM among patients with white punctuation and in the control group. In DM and hyperglycemia infectious diseases are common. The main reason for this is the emergence of an immunosuppressive condition as a result of natural and acquired immunity disorders. In mouse DM models, phagocytosis, chemotaxis and cytokine production with neutrophil functions are decreased. In patients with DM, the belt toward the TH2-axis leads to a decrease in Th1-dependent immunity [5]. In a study involving 200 diabetic and 200 dyspeptic patients in Turkey, giardia intestinalis was investigated in the stool by ELISA method and giardiasis was found in $7 \%$ of dyspeptic patients and $15 \%$ in diabetic patients [6].

Giardiasis is one of the pathologies that accompany white spots and. It is very common in our country [7]. Therefore, we hypothesized that DM may be the underlying disease of the white spots. But when we investigated the relationship between DM and white spots; we could not find a significant relationship. We could detect giardiasis in only 2 patients histopathologically and we think that our study could have been more valuable if we had also tested giardia antigen in stool by Enzyme-Linked ImmunoSorbent Assay (ELISA) in these patients which is the most sensitive method. In the literature, there is no study investigating the relations between DM and white spots.

Anemia is also a finding in giardiasis [8]. The cause of anemia is the disruption disrupt of iron absorption by this parasite. In 302 children who went to kindergarten in Tunisia, giardiasis and anemia were investigated and the rate of anemia was $23.17 \%$ in the presence of giardiasis infection [9]. We also thought that there might be a relationship between anemia and white spots, and we compared patients with white spots to those who did not. We could not detect any relationship between anemia and white spots. In the literature, there are no studies on the relationship between anemia and white spots.

Helicobacter pylori (H. pylori) are present in roughly $50 \%$ of the human population worldwide and infection levels reach over $70 \%$ in developing countries. One of the main mechanisms by which $H$. pylori is thought to damage the host is by inducing local and systemic inflammation [10,11]. From this point of view, we investigated the relationship of white spots in duodenum with MPV and RDW, PLR, NLR, which are nowadays used as markers of inflammation in many systemic diseases.

Neutrophil lymphocyte ratio is a parameter of neutrophil count associated with lymphocyte division. In recent studies, NLR is said to be a marker of systemic inflammation in many diseases such as atherosclerosis, myocardial infarction, DM, ulcerative colitis, and malignancies $[12,13]$. NLR has been shown to be superior to the white blood cell (WBC) in predicting adverse effects in various inflammatory and surgical conditions (i.e, pancreatitis, appendicitis, acute coronary syndrome, major vascular surgery and critical care disease) $[12,14]$. We compared the NLR between the patients with white spots and those who were not present in order to determine whether the white spots are related to inflammation. However, we could not find any significant difference. In the literature, there are no studies investigating the relation between white pointing and NLR. The platelet lymphocyte ratio (PLR) is the parameter of the number of platelets divided by the number of lymphocytes. In recent studies, PLR is said to be an indicator of systemic inflammation $[15,16]$. Therefore, we compared the patients with white spots and those who were not. However, we could not find a significant difference. There is no study investigating the relationship between white pointing with PLR in the literature. In recent years, it has been reported that MPV can be used as a marker of inflammation in different inflammatory diseases. Inflammatory, pro-inflammatory cytokines and acute phase markers in the inflammatory process on the bone marrow affect megakaryopoiesis and this may cause a decrease in platelet volume [17]. In the study of Kapsoritakis, MPV levels were found lower in inflammatory bowel disease compared to the healthy group [18]. Cardiovascular risk factors such as smoking, hypertension, dyslipidemia and diabetes may affect MPV. Active platelets play a role in cancer progression and metastases. Mean platelet volume (MPV) is an indicator of activated platelets and is associated with gastric, breast, lung, colon and ovarian cancers [19]. We compared whether there is a difference in MPV between patients with white spots and non-patients. However, we could not detect significant differences. In the literature, there is no study investigating the relationship between MPV and white spots. 
Two limitations of present work are retrospective design and relatively small study population. However, our results may contribute to current literature, significantly.

It has been suggested that RDW is associated with a strong and independent risk of cardiovascular morbidity and mortality in patients with previous myocardial infarction and higher RDW levels may reflect an underlying chronic inflammation that would increase the risk of cardiovascular disease [20]. RDW's studies have shown that it is a marker of inflammation. We did not find a relationship between RDW and white spots. In the literature, there is no study investigating the relationship between RDW and white spots.

\section{CONCLUSION}

Both diabetes mellitus and H. pylori are causes of systemic inflammation. In our study, we evaluated whether patients with white spots were associated with systemic inflammation by looking at popular inflammation markers. We could not find any difference between the two groups in terms of these markers.

\section{AUTHORS' CONTRIBUTION}

Ozge Kurtkulagi did the retrospective investigation, analyzed the data and wrote the paper. Ozlem Yonem designed the study and wrote the paper.

\section{FUNDING}

The authors have received no funding for this article.

\section{CONFLICT OF INTEREST}

Declared none.

\section{ACKNOWLEDGEMENTS}

We acknowledge all our patients for their participation in the study.

\section{REFERENCES}

[1] Veldhuyzen van Zanten SJ, Bartelsman JF, Tytgat GN. Endoscopic diagnosis of primary intestinal lymphangiectasia using a high-fat meal. Endoscopy 1986; 18(3): 108-10. DOI: 10.1055/s-2007-1018344

[2] Biyikoğlu I, Babali A, Çakal B, et al. Do scattered white spots in the duodenum mark a specific gastrointestinal pathology? J Dig Dis 2009; 10(4): 300-4. DOI: 10.1111/j.1751-2980.2009.00399.x

[3] García-Sancho M, Sainz Á, Villaescusa A, Rodríguez A, Rodríguez-Franco F. White spots on the mucosal surface of the duodenum in dogs with lymphocytic plasmacytic enteritis. J Vet Sci 2011; 12(2): 165-9. DOI: 10.4142/jvs.2011.12.2.165
[4] Taş A, Koklu S, Beyazit Y, et al. The endoscopic course of scattered white spots in the descending duodenum: A prospective study. Gastroenterol Hepatol 2012; 35(2): 57-64. DOI: 10.1016/j.gastrohep.2011.11.010

[5] Tanaka Y. Immunosuppressive mechanisms in diabetes mellitus. Nihon Rinsho 2008; 66(12): 2233-7.

[6] Hakim GD, Kızıltaş Ş, Ciftçi H, Göktaş Ş, Tuncer I. The prevalence of giardia intestinalis in dyspeptic and diabetic patients. ISRN Gastroenterol 2011; 2011: 580793. DOI: $10.5402 / 2011 / 580793$

[7] Barrós P, Bussalleu A, Tello R, Berríos J. The prevalence of giardiasis in patients who undergo gastroduodenoscopy. Rev Gastroenterol Peru 1994; 14(3): 215-21.

[8] Cabada MM, Goodrich MR, Graham B, et al. Prevalence of intestinal helminths, anemia, and malnutrition in Paucartambo, Peru. Rev Panam Salud Publica 2015; 37: 69-75.

[9] Gharbi T, Chaker E, Boughedir J, el Mabrouk S, Rayana B. Study of anemia in giardiasis intestinalis in Tunisian preschool children. Tunis Med 1999; 77(11): 558-61.

[10] Bravo D, Hoare A, Soto C, Valenzuela MA, Quest AF. Helicobacter pylori in human health and disease: Mechanisms for local gastric and systemic effects. World J Gastroenterol 2018; 24(28): 3071. DOI: 10.3748/wjg.v24.i28.3071

[11] Camilo V, Sugiyama T, Touati E. Pathogenesis of helicobacter pylori infection. Helicobacter 2017; 22: e12405. DOI: 10.1111/hel.12405

[12] Torun S, Tunc BD, Suvak B, et al. Assessment of neutrophil-lymphocyte ratio in ulcerative colitis: A promising marker in predicting disease severity. C Clin Res Hepatol Gastroenterol 2012; 36(5): 491-7. DOI: 10.1016/j.clinre.2012.06.004

[13] Yin Y, Wang J, Wang X, et al. Prognostic value of the neutrophil to lymphocyte ratio in lung cancer: A meta-analysis. Clinics 2015; 70(7): 524-30. DOI: 10.6061/clinics/2015(07)10

[14] Forget P, Khalifa C, Defour J-P, Latinne D, Van Pel M-C, De Kock M. What is the normal value of the neutrophil-to-lymphocyte ratio? BMC Res Notes 2017; 10(1): 12. DOI: 10.1186/s13104-016-2335-5

[15] Ma Y, Mao Y, He X, Sun Y, Huang S, Qiu J. The values of neutrophil to lymphocyte ratio and platelet to lymphocyte ratio in predicting 30 day mortality in patients with acute pulmonary embolism. BMC Cardiovasc Disord 2016; 16(1): 123. DOI: $10.1186 /$ s12872-016-0304-5

[16] Mertoglu C, Gunay M. Neutrophil-Lymphocyte ratio and Platelet-Lymphocyte ratio as useful predictive markers of prediabetes and diabetes mellitus. Diabetes Metab Syndr 2017; 11: S127-S31. DOI: 10.1016/j.dsx.2016.12.021

[17] Erre GL, Paliogiannis P, Castagna F, et al. Meta冈analysis of 


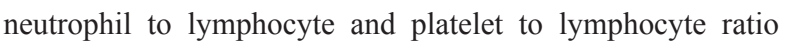
in rheumatoid arthritis. Eur J Clin Invest 2019; 49(1): e13037. DOI: $10.1111 /$ eci.13037

[18] Kapsoritakis AN, Koukourakis MI, Sfiridaki A, et al. Mean platelet volume: A useful marker of inflammatory bowel disease activity. Am J Gastroenterol 2001; 96(3): 776-81. DOI: $10.1111 / \mathrm{j} .1572-0241.2001 .03621 . \mathrm{x}$

[19] Qin Y-Y, Wu Y-Y, Xian X-Y, et al. Single and combined use of red cell distribution width, mean platelet volume, and cancer antigen 125 for differential diagnosis of ovarian cancer and benign ovarian tumors. J Ovarian Res 2018; 11(1): 10.DOI: $10.1186 / \mathrm{s} 13048-018-0382-3$

[20] Lippi G, Targher G, Montagnana M, Salvagno GL, Zoppini G, Guidi GC. Relation between red blood cell distribution width and inflammatory biomarkers in a large cohort of unselected outpatients. Arch Pathol Lab Med 2009; 133(4): 628-32. DOI: 10.5858/133.4.628

Received: December 23, 2020

(C) 2020 National Journal of Health Sciences.

This is an open-access article. 